\title{
Research on Design Evaluation of L-shaped Kitchen Cabinets Based on Fuzzy Analytic Hierarchy Process
}

\author{
Siyuan Chen ${ }^{1}$, Jianhua Lyu ${ }^{1,2, *}$, Zhihui Pang ${ }^{1}$ and Ming Chen ${ }^{1,2}$ \\ ${ }^{1}$ Forestry College, Sichuan Agricultural University, Chengdu 611130, China \\ ${ }^{2}$ Wood Industry and Furniture Engineering Key Laboratory of Sichuan Provincial Department of Education, Sichuan Agricultural \\ University, Chengdu 611130, China
}

\begin{abstract}
Based on fuzzy analytic hierarchy process, this paper studied and established a comprehensive evaluation model of L-shaped kitchen cabinets from four aspects, which are as follows: functionality, aesthetics, economy and safety, the weight value of each attribute was calculated, then the model was applied to a kitchen cabinet product design. The results show that the economic and safety factors have high weight values in the kitchen cabinets product design, which means those aspects of kitchen cabinets product design should be adjusted to improve overall performance. FAHP has high feasibility and effectiveness in the practices of comprehensive evaluation, which can provide a reference for the evaluation and optimization of kitchen cabinets product design.
\end{abstract}

\section{Introduction}

The kitchen cabinets are centered on kitchen furniture, combining furniture and kitchen equipment, and matching the style of decoration[1]. Common kitchen layout types include L-shaped, U-shaped, straight and island-shaped. Restricted by the area of the kitchen, $79 \%$ of the users in China choose the layout of straight and L-shaped kitchens, of which $41 \%$ choose the layout of L-shaped[2]. Including cabinets, countertops, decorative panels, hardware accessories and other accessories, kitchen cabinets are a typical split structure. Since the product evaluation process involves multiple levels, the introduction of FAHP for the kitchen cabinet can convert the subjective qualitative evaluation into quantification, which is conducive to providing effective references for cabinet designers and operators[3].

\section{FAHP Theory}

AHP was proposed by Professor Thomas L. Saaty of the University of Pittsburgh in 1971. It can turn complex problems into system-level problems and compare the importance of each element[4]. However, this method tends to be subjective in the establishment of hierarchical relationships, and is susceptible to extreme values in data analysis. Therefore, scholars introduce the fuzzy number theory into AHP to form FAHP to solve the problem[5].

\section{Construction of evaluation index system for L-shaped kitchen cabinets}

\subsection{Criteria layer settings}

Distribute questionnaires to people of different ages, income levels, family types and occupation types to collect the factors that influence their purchase of cabinets. The survey results are shown in Figure 1. According to the survey results, the criterion layer is summarized into four indicators: functionality, aesthetics, economy and safety.

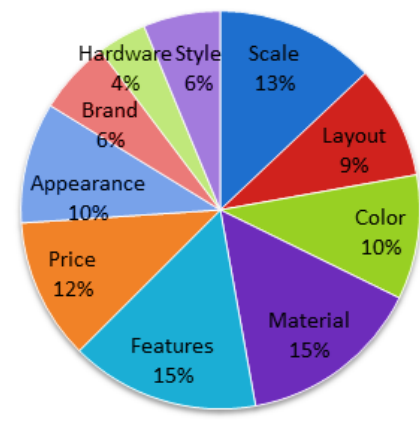

Fig1. Factors influencing consumers' purchase of cabinets

\footnotetext{
*Corresponding author's e-mail: 1jh@sicau.edu.cn
} 


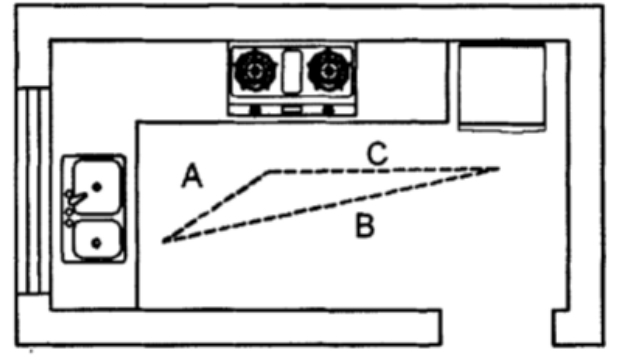

Fig2. L-shaped kitchen work triangle

\subsection{Behavior layer division}

\subsubsection{Function and scale analysis.}

The basic practical functions of kitchen cabinets are cooking, washing and storage, which can divide the L-shaped kitchen cabinet into three areas, including the cooking operation area centered on the stove, the washing and meal preparation area centered on the sink, and the storage area centered on the refrigerator. Connect the three points to form a working triangle. (Figure 2) This layout has short moving lines, which can greatly improve operation efficiency [6]. The accessories required for the realization of each function are shown in Table 1.

Table 1. Basic functions and related accessories of L-shaped cabinets

\begin{tabular}{ll}
\hline $\begin{array}{l}\text { Product } \\
\text { Features }\end{array}$ & Related accessories \\
\hline $\begin{array}{l}\text { Storage } \\
\text { function }\end{array}$ & Wall cabinets, floor cabinets, high \\
& cabinets, drawers, baskets, hooks, \\
storage compartments, countertops \\
function & Sink, upper water pipe, lower water \\
Cooking & pipe \\
function & Stove, trachea transportation or gas \\
\hline
\end{tabular}

The function of kitchen cabinets is closely related to the size selection. Within the effective range, the length of the longer side of the L-shaped should not be less than $1.7 \mathrm{~m}$, and the longer side should be about $2.8 \mathrm{~m}$. The distance between the pool and the stove should be 1.2 $1.8 \mathrm{~m}$, the distance between the refrigerator and the stove should be $1.2 \sim 2.7 \mathrm{~m}$, and the distance between the refrigerator and the sink should be $1.2 \sim 2.1 \mathrm{~m}$. The sink and the corner should leave more than $30 \mathrm{~cm}$ of activity space[7]. The basic kitchen cabinet space operation scale is shown in Figure 3. The cabinet height and frequency of use are shown in Figure 4.

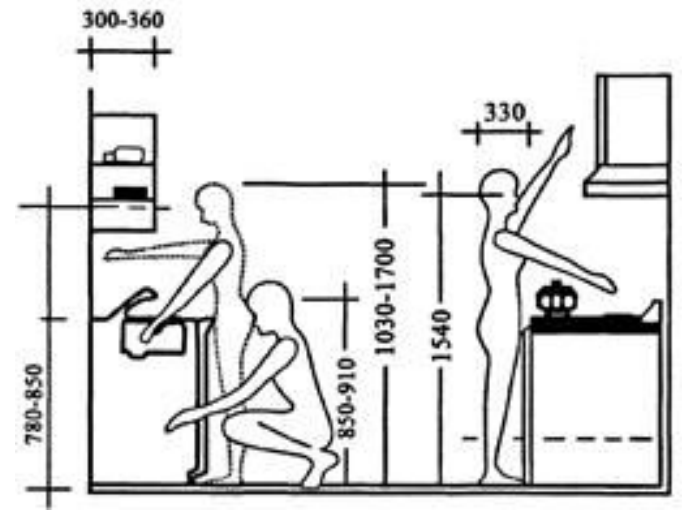

Fig3. Human space operation scale

\begin{tabular}{|c|c|}
\hline Rarely use & $\mathrm{H}: 1850 \sim 2300 \mathrm{~mm}$ \\
\hline $\begin{array}{l}\text { Commonly use } \\
\text { Con }\end{array}$ & $\mathrm{H}: 1500 \sim 1850 \mathrm{~mm}$ \\
\hline $\begin{array}{l}\text { High frequency } \\
\text { use }\end{array}$ & $\mathrm{H}: 800 \sim 1500 \mathrm{~mm}$ \\
\hline Commonly use & $\mathrm{H}: 400 \sim 800 \mathrm{~mm}$ \\
\hline Rarely use & $\mathrm{H} \leq 380 \mathrm{~mm}$ \\
\hline
\end{tabular}

Fig4. Cabinets' height and frequency of use

\subsubsection{Materials analysis.}

As shown in Table 2, due to the multiple materials involved, the product structure of the L-shaped kitchen cabinet is complex. Based on the above analysis, 16 items to be evaluated are summarized. According to FAHP, all indicators are divided into 3 levels, including target level A, criterion level B and behavior level C. As shown in Figure 5, the evaluation index system of L-shaped kitchen cabinet is constructed.

Table 2. Material elements of L-shaped kitchen cabinets

\begin{tabular}{ll}
\hline $\begin{array}{l}\text { Product unit } \\
\text { structure }\end{array}$ & Material types \\
\hline Cabinet & $\begin{array}{l}\text { Block board, particle board, MDF, } \\
\text { solid wood, etc. } \\
\text { Refractory door panels, solid wood } \\
\text { door panels, painted door panels, } \\
\text { PVC plastic door panels, metal door } \\
\text { panels, crystal panels, etc. }\end{array}$ \\
& $\begin{array}{l}\text { Artificial stone, stainless steel, } \\
\text { natural stone, fireproof plate, etc. }\end{array}$ \\
Countertops & $\begin{array}{l}\text { Hinge, slide rail, pressure device, } \\
\text { pull basket, pulley, seal, handle, etc. }\end{array}$ \\
\hline
\end{tabular}




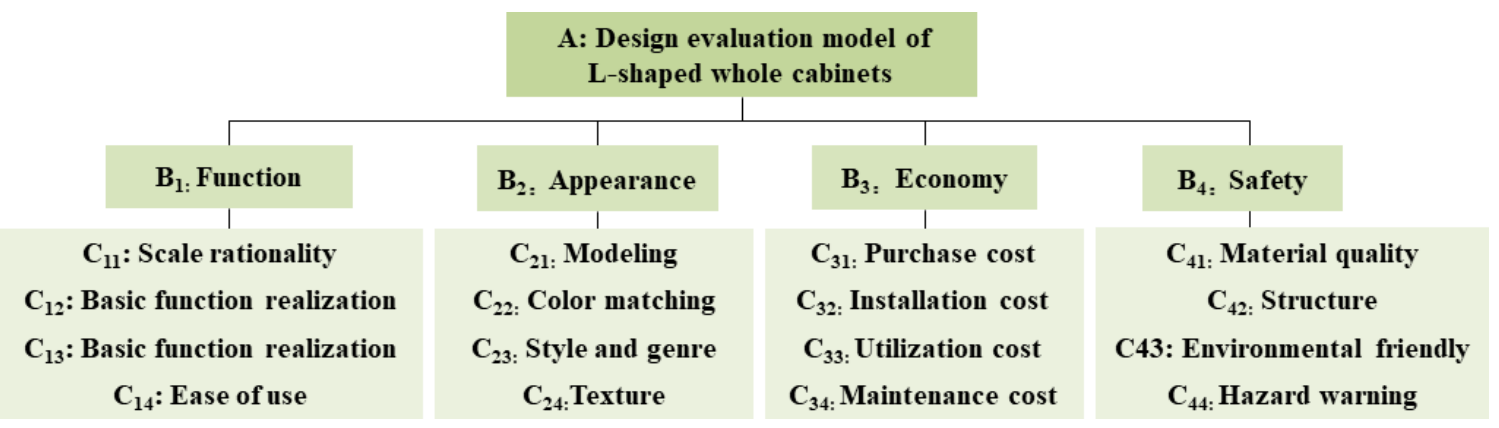

Fig5. Evaluation index system of L-shaped kitchen cabinets

\section{Illustration analysis}

Taking the L-shaped kitchen cabinet in Chongqing as an example, the cabinet and layout are shown in Figure 6 and Figure 7. The cabinet material is multi-layer solid wood composite board, the door board material is baking paint board, and the countertop material is artificial marble. The decoration cost of cabinets is about 20,000 $¥$, accounting for $10 \%$ to $20 \%$ of the entire interior decoration.

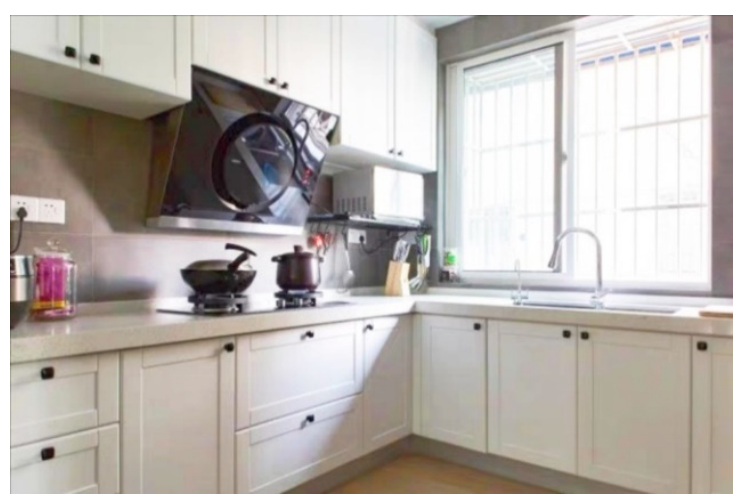

Fig6. An L-shaped kitchen cabinet

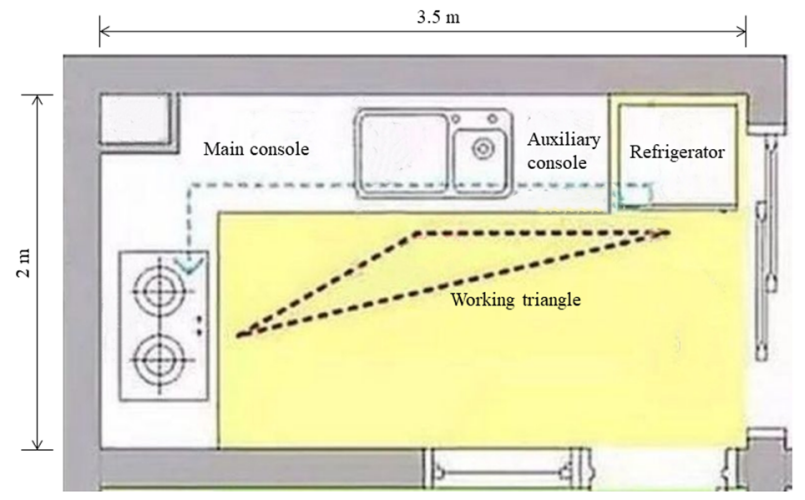

Fig7. Plane rendering of an L-shaped kitchen cabinet

\subsection{Construction of judgment matrix}

In order to calculate the weight value of each layer, the judgment matrixes were constructed by pairwise comparison, and the importance was expressed according to the comparison scale of 1-9[8]. Taking the L-shaped kitchen cabinet as the evaluation object, the expert group completed the analytic hierarchy questionnaire. The judgment matrixes of the behavior layer are shown in Table $3 \sim 6$.

Table 3. Functional judgment matrix

\begin{tabular}{ccccc}
\hline $\mathrm{B}_{1}$ & $\mathrm{C}_{11}$ & $\mathrm{C}_{12}$ & $\mathrm{C}_{13}$ & $\mathrm{C}_{14}$ \\
\hline $\mathrm{C}_{11}$ & 1 & 2 & 3 & 2 \\
$\mathrm{C}_{12}$ & $1 / 2$ & 1 & 4 & 3 \\
$\mathrm{C}_{13}$ & $1 / 3$ & $1 / 4$ & 1 & $1 / 2$ \\
$\mathrm{C}_{14}$ & $1 / 2$ & $1 / 3$ & 2 & 1 \\
\hline
\end{tabular}

Table 4. Appearance judgment matrix

\begin{tabular}{ccccc}
\hline $\mathrm{B}_{2}$ & $\mathrm{C}_{21}$ & $\mathrm{C}_{22}$ & $\mathrm{C}_{23}$ & $\mathrm{C}_{24}$ \\
\hline $\mathrm{C}_{21}$ & 1 & 4 & 3 & 1 \\
$\mathrm{C}_{22}$ & $1 / 4$ & 1 & $1 / 2$ & $1 / 2$ \\
$\mathrm{C}_{23}$ & $1 / 3$ & 2 & 1 & 1 \\
$\mathrm{C}_{24}$ & 1 & 2 & 1 & 1 \\
\hline
\end{tabular}

Table 5. Economic judgment matrix

\begin{tabular}{ccccc}
\hline $\mathrm{B}_{3}$ & $\mathrm{C}_{31}$ & $\mathrm{C}_{32}$ & $\mathrm{C}_{33}$ & $\mathrm{C}_{34}$ \\
\hline $\mathrm{C}_{31}$ & 1 & 3 & 2 & 2 \\
$\mathrm{C}_{32}$ & $1 / 3$ & 1 & $1 / 4$ & $1 / 2$ \\
$\mathrm{C}_{33}$ & $1 / 2$ & 4 & 1 & 2 \\
$\mathrm{C}_{34}$ & $1 / 2$ & 2 & $1 / 2$ & 1 \\
\hline
\end{tabular}

Table 6. Security judgment matrix

\begin{tabular}{ccccc}
\hline $\mathrm{B}_{4}$ & $\mathrm{C}_{41}$ & $\mathrm{C}_{42}$ & $\mathrm{C}_{43}$ & $\mathrm{C}_{44}$ \\
\hline $\mathrm{C}_{41}$ & 1 & 3 & 2 & 4 \\
$\mathrm{C}_{42}$ & $1 / 3$ & 1 & $1 / 3$ & $1 / 2$ \\
$\mathrm{C}_{43}$ & $1 / 2$ & 3 & 1 & 4 \\
$\mathrm{C}_{44}$ & $1 / 4$ & 2 & $1 / 4$ & 1
\end{tabular}

\subsection{Weight calculation and consistency test of various factors}

Solve the weight vector of each judgment matrix and check the consistency. The formulas included in the calculation steps are as follows:

$$
\begin{gathered}
M_{i}=\prod_{j=1}^{m} a_{i j}(i=1,2, \cdots, m) \\
w_{i}=\left(M_{i}\right)^{1 / m} \\
W_{i}=w_{i} / \sum_{i=1}^{m} w_{i} \\
C I=\lambda_{\max }-n / n-1 \\
C R=C I / R I
\end{gathered}
$$


According to the method, weight vectors of the criterion layer and the relative indicator layer were calculated. As shown in Table 7, the fuzzy judgment matrix of the L-shaped kitchen cabinet is $\mathrm{A}=\left[\begin{array}{ll}0.25 & 0.11\end{array}\right.$ $0.300 .32]$.

Table 7. Calculation results and consistency test of L-shaped kitchen cabinet evaluation index

\begin{tabular}{|c|c|c|c|c|}
\hline \multicolumn{2}{|c|}{ Criteria layer } & \multicolumn{2}{|c|}{ Indicator layer } & \multirow{2}{*}{$\begin{array}{c}\text { Consistency } \\
\text { test }\end{array}$} \\
\hline Index & Weight & Index & Weight & \\
\hline \multirow{4}{*}{$\mathrm{B}_{1}$} & \multirow{4}{*}{0.25} & $\mathrm{C}_{11}$ & 0.38 & $\lambda_{\max }=4.14$ \\
\hline & & $\mathrm{C}_{12}$ & 0.32 & $\mathrm{CI}=0.05$ \\
\hline & & $\mathrm{C}_{13}$ & 0.09 & $\mathrm{CR}=0.05$ \\
\hline & & $\mathrm{C}_{14}$ & 0.15 & $\mathrm{CR}<0.1$ \\
\hline \multirow{4}{*}{$\mathrm{B}_{2}$} & \multirow{4}{*}{0.11} & $\mathrm{C}_{21}$ & 0.42 & $\lambda_{\max }=4.09$ \\
\hline & & $\mathrm{C}_{22}$ & 0.11 & $\mathrm{CI}=0.03$ \\
\hline & & $\mathrm{C}_{23}$ & 0.20 & $\mathrm{CR}=0.04$ \\
\hline & & $\mathrm{C}_{24}$ & 0.27 & $\mathrm{CR}<0.1$ \\
\hline
\end{tabular}

\subsection{Fuzzy comprehensive evaluation}

A review set of evaluation objects $\mathrm{V}=\left\{\mathrm{v}_{1}, \mathrm{v}_{2} \ldots \mathrm{v}_{\mathrm{m}}\right\}=$ \{satisfied, general, dissatisfied, very dissatisfied\} was used to express perception. The corresponding score levels are $0.8,0.6,0.4$ and 0.2 . The comprehensive evaluation score of the cabinet is 0.63 , indicating that the product can basically meet the needs of users. The advantages of the product are reasonable scale, satisficed basic functions, and environmentally friendly materials. The disadvantage is that the appearance is insufficient, and the development of extended functions needs to be strengthened.

$\mathrm{U}=\left(\begin{array}{llll}0.25 & 0.11 & 0.30 & 0.32\end{array}\right)\left(\begin{array}{l}0.64 \\ 0.67 \\ 0.66 \\ 0.62\end{array}\right)=0.63$

\section{Conclusion}

The article used FAHP to establish a comprehensive evaluation model of L-shaped kitchen cabinets from four aspects of functionality, aesthetics, economy and safety, and used this model to evaluate a cabinet product. The results show that it is feasible to apply FAHP to the evaluation of kitchen cabinets, and the economy and safety of kitchen cabinets are increasingly concerned by consumers. As the main furniture of the kitchen, the cabinet has both basic and spiritual functions. While exploring the hidden needs of users, enterprises must also pay attention to cost control and environmental protection of materials.

\section{Acknowledgments}

The authors are grateful for the support of Opening Foundation for Industrial Design Industry Research Center, Key Research Base of Humanities and Social Sciences, Sichuan Education Department (GYSJ18-037), and Project of Modern Design and Culture Research

\begin{tabular}{ccccc}
\hline \multicolumn{2}{c}{ Criteria layer } & \multicolumn{2}{c}{ Indicator layer } & \\
\cline { 1 - 3 } Index & Weight & Index & Weight & Consistency test \\
& & $\mathrm{C}_{31}$ & 0.41 & \\
& & $\mathrm{C}_{32}$ & 0.10 & $\mathrm{CI}=0.03$ \\
$\mathrm{~B}_{3}$ & 0.30 & $\mathrm{C}_{33}$ & 0.31 & $\mathrm{CR}=0.04$ \\
& & $\mathrm{C}_{34}$ & 0.18 & $\mathrm{CR}<0.1$ \\
& & $\mathrm{C}_{41}$ & 0.46 & $\lambda_{\max }=4.17$ \\
& & $\mathrm{C}_{42}$ & 0.10 & $\mathrm{CI}=0.06$ \\
$\mathrm{~B}_{4}$ & 0.32 & $\mathrm{C}_{43}$ & 0.32 & $\mathrm{CR}=0.06$ \\
& & $\mathrm{C}_{44}$ & 0.12 & $\mathrm{CR}<0.1$ \\
\hline
\end{tabular}

Center, Sichuan Key Research Base of Philosophy and Social Sciences (Grant No. MD18Z002).

\section{References}

1. Xiaowei G. (2017) Research on the development and present situation of the integrated Kitchen cabinet in China. Furniture, 38(04): 39-41+84.

2. Liwei H., Wanjiang W., Yonggang P. (2015) Research on kitchen space in relation to behavior pattern. Journal of Henan University (Natural Science), 45(06): 752-756.

3. Xiaolei C., Jun S., Jianping S. (2015) A fuzzy comprehensive evaluation model for kitchen cabinet schemes based on analytic hierarchy process. Journal of Forest and Environment, 35(02): 179-184.

4. Liangchun L., Jicheng G., Zhongquan L., etc. (2016) Outsourcers selection of military packaging based on FAHP. Packaging Engineering, 37(01): 56-60.

5. Changxue P., Huang Z., Xinhui K., etc. (2019) Appearance design of home exercise bike based on FAHP method. Packaging Engineering, 40(12): 175-182.

6. Li 1., Huiyuan G. (2018) Discussion on the functional module design of kitchen cabinet. Furniture, 39(01): 64-67.

7. Jianfeng Z. (2011) Modern kitchen design and cabinet manufacturing. Chemical Industry Press, Beijing.

8. Liu Y., Tianxiong W., Runmei Z. (2019) Evaluation and application of intelligent rice cooker design based on fuzzy analytic hierarchy process. Packaging Engineering, 36(04): 129-133. 